\title{
浅析“互联网 +”背景下高职院校《形势与政策》教学的有效方式
}

\section{On the Effective Way of Teaching "Situation and Policy" in Higher Vocational Colleges under the Background of "Internet $+"$}

庄西艳

Xiyan Zhuang

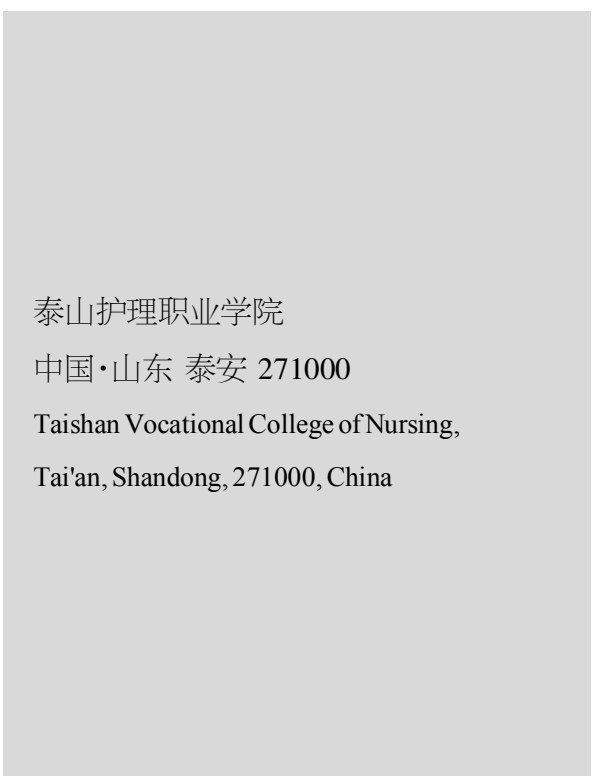

【摘 要】在“互联网 + ”的大背景下, 《形势与政策》课程的教学和实践方式迎来了挑战和 创新, 为了不断加强和促进《形势与政策》课程规范性建设, 发挥其育人的功能, 课题组对 目前高职院校《形势与政策》课的建设和教学实践现状进行了深入的调查和分析, 积极探 索《形势与政策》课程教学的有效方式。

【Abstract】Under the background of "Internet +", the teaching and practice mode of "situation and policy" has ushered in challenges and innovations. In order to constantly strengthen and promote the standardized construction of situation and policy and give full play to its function of educating people, the task group made an in-depth investigation and analysis of the current situation and policy of the higher vocational colleges, and actively explored the current situation of teaching practice. Find out the effective way of teaching situation and policy.

【关键词】互联网 + ; 高职院校; 教学形势与政策; 有效教学方式

【Keywords】Internet +; vocational colleges; teaching situation and policies; effective teaching methods.

【DOI】10.36012/sde.v2i2.1259

\section{1 引言}

在现代化教育和信息化的大发展背景下，“互联网+”是 以应用互联网技术为主的一整套现代信息技术在人类经济社 会和生活中各个职能部门的广泛扩散和综合应用的过程。高 职院校学生对于网络的接受度很高, 通过对互联网的学习, 能 够及时获取大量的信息, 掌握知识, 拓宽视野。为了增强《形式 与政策》理论课的教学有效性,必须充分利用好“联网+”的优 势, 积极探索《形势与政策》课程教学的有效方式, 不断促进 《形势与政策》课教学规范性的建设。为深人了解高职院校《形 势与政策》课具体的教学情况, 我们利用网络调查问卷的形 式, 分别对中国泰安市五所高职院校的教学情况进行调查。

\section{2 高职院校《形势与政策》课程的教学现状}

本次问卷调查显示各院校都能够有效保证该课的平均教 学时数和学分; 在教学的形式上, 采取每学期课堂讲授、专题
讲座、请专家做报告等; 在授课时间的安排上, 安排在正常进 行教学的时间; 在教学成绩考核的方式上, 采取根据学生所撰 写毕业论文及学生课堂考勤各部分占一定比例的方式综合评 定教学成绩; 在对教材的使用方面, 能够按照教育部《形势与 政策教育教学要点》的规定和要求授课; 在教学手段上, 教师 在课堂上能经常使用多媒体教学; 学生在对开设《形势与政 策》的认识上, $60.18 \%$ 的学生“非常清楚”; 在对《形势与政策》 的教学内容开设有效性上, $44.8 \%$ 学生认为“有效性很强”; 对 目前《形势与政策》高校开设课的实际教学效果, $43.6 \%$ 的高 校学生普遍认为“较好”, $50.18 \%$ 的学生普遍认为“一般”; 本 次调查分析结果说明, 多数高职学生对《形势与政策》课开设 的意义和重要性基本上是持认同的态度，但多数学生对学习 这门课的兴趣和积极性不高, 这也充分说明高职院校需要进 一步提高《形势与政策》课程教学的质量和有效性,进一步创 新和探索《形势与政策》教学的有效方式。 


\section{3 影响《形势与政策》课程的教学质量和 有效性的主要原因}

\section{1 缺乏统一的教学规范管理}

调查结果显示有些院校《形势与政策》课程的教学行为缺 乏统一的规范管理,《形势与政策》课程虽以必修为主,但有些 院校采取了大班教学, 主要以课堂授课、专题讲座、形势调查 报告、观看纪录片和音像视频资料等多种教学方式在课堂进 行, 课堂师生互动的活动少, 师生间的沟通交流少, 导致了学 生对于《形势与政策》课程的基本认识和理解不足, 参与相关 理论学习的自主性也不强, 《形势与政策》课程的有效性也大 大降低。

\section{2 师资队伍建设有待进一步加强}

《形势与政策》授课教师主要由担任思政课的专任教师、 学院党政机关干部、辅导员等组成,有些院校未对《形势与政 策》课程的教师开展相应的系统化和规范化的专业培训, 但是 《形势与政策》课程内容繁杂, 部分授课教师因为平时的工作 较忙, 没有足够的时间和精力去广泛收集教学资料和深人地 研究教学问, 再加上不充分了解教师和学生的需求, 就可能会 在教学过程中出现照本宣科的现象, 大大降低了形势与政策 课的教学效果，因此高校需要进一步提高授课教师的知识和 教学技术水平 ${ }^{[1]}$ 。

\section{3 学生上课的积极性有待提高}

在信息化时代, 学生可以通过互联网了解到大量时政新 闻,但获得的信息大多是碎片化和不完整的,需要通过上《形 势与政策》课形成体系。要想进一步提高《形势与政策》课的 教学有效性, 就必须针对教师和学生的新知识需求进行针对 性的改进。但《形势与政策》课教学内容的滞后性等诸多因素 严重降低了学生上课的学习积极性, 对《形势与政策》课的社 会理论学习活动兴趣不高, 缺乏了上课的积极性。

\section{4 缺乏有针对性的实践教学}

有些院校还没有建立《形势与政策》课程的社会实践教 育基地，《形势与政策》课程的实践教学实施不到位, 也没有 有计划有针对性地组织学生积极参加社会实践考察等活动, 学生对当地的政治经济社会缺乏具体的了解和认识, 从而直 接影响到学生对《形势与政策》课知识的把握和体验。

\section{4 加强《形势与政策》课程教学的有效实 施方式}

\section{1 加强教学组织和领导, 实行规范教学和管理}

《形势与政策》课程是大学生思想政治教育理论课的极其 重要内容和组成部分, 各院校必须进一步加强《形势与政策》
理论课的教学和组织工作, 提高其认识, 统一其指导思想, 不 断完善统一管理机制,实行统一的规范教学管理, 以更好地确 保《形势与政策》课教学的有效组织和实施。

\section{2 充分突显当前高职特色, 创新和完善教学方式}

当前高职思想政治教育的特色是要培养拥护中国共产党 的基本路线，适应中国新时代经济社会发展改革创新需要的 德智体美劳全面发展的技术人才。因此, 高职院校《形势与政 策》课程的开设和教学工作(主要包括教学内容、形式和教学 方法等) 必须充分体现和紧紧地围绕这一教学特色和目标来 进行, 要不断地进行思想政治教学理论的研究和教改活动实 践, 从而积极地创新和完善高职思想政治教育的方式 ${ }^{[2]}$ 。《形 势与政策》课程在其教学方法上必须充分注重教学的针对性、 灵活性和教学的政策性, 应多增加一些促进师生交流互动的 环节, 活跃和谐的课堂气氛, 应定期组织或激请校外发展政策 专家、模范海外标兵和优秀海外校友等校举行国际有关时政 热点国际形势的分析报告, 也可以在高职院校园网上定期设 立国际形势与政策相关专题的网站和论坛等。

\section{3 进一步加强师资队伍建设, 提高教学质量}

高职院校应对《形势与政策》授课师资队伍的建设工作进 行统一长远的教学发展规划, 根据学校的实际教学发展情况, 有计划、有针对性地努力培养稳定的高素质教学师资队伍。授 课教师不断地提高思想政治理论素养和教师的专业素质, 提 高获取信息的渠道和能力提高学生整合新闻信息的意识和能 力, 授课教师还必须要具有对时政和新闻敏锐性, 能及时地把 最新的中国时政和内容准确地传递出来给学生。

\section{4 充分改进教学手段,提高学生上课积极性}

课堂上,采取教师与小组互动交流的教学形式,让更多的 学生通过小组活动, 增强了学生的解决实际问题的能力; 或者 充分运用传统的马克思主义的观点和教学方法, 与小组的学 生对其关心的教学热点难点和疑点问题进行深入的讨论和分 析; 充分利用教师课下线上与小组的学生之间进行的交流和 沟通, 从而不断地培养广大学生的分析、解决生活存在问题的 意识和能力, 帮助广大学生进一步提高对问题的认识, 增强课 堂教学效果; 或者借助于移动互联网, 拓宽了学生课堂的教学 信息量,挖掘丰富的课堂教学资源, 提高了学生课堂教学的整 体形象性和课堂教学中的趣味性。

\section{5 整合教学资源, 开展实践基地教学}

高职院校的教师应充分结合其办学特色，有效地整合校 内外的实践教学资源, 积极开展《形势与政策》课程的实践教 


\section{课程教材 Course Material}

定义方法,用于判断正整数 $\mathrm{N}$ 和 $\mathrm{M}$ 是否互质。

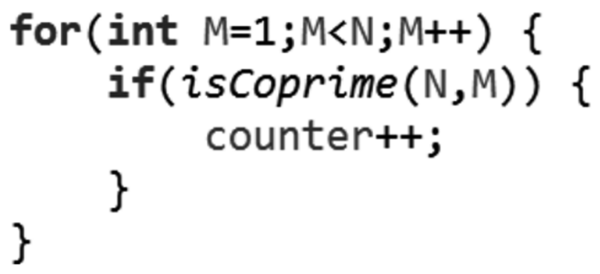

图 2 判断 $N$ 和 $M$ 是否互质

\section{2 获得正整数 $M$ 和 $N$ 的因子，并将因子保存}

\section{到集合}

获得 $\mathrm{M}$ 和 $\mathrm{N}$ 的各自因子, 并分别保存到两个集合对象 中, 此处使用 ArrayList 类中的常用方法 add(Object o)进行数 据存储。

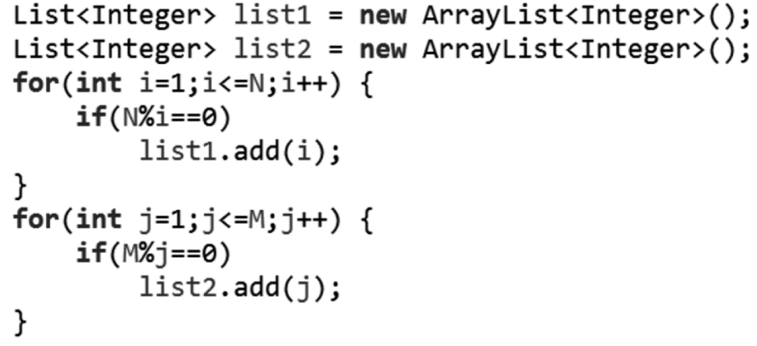

图 3 获得并保存正整数 $N$ 和 $M$ 的各自因子

\section{3 判断 $M$ 和 $N$ 是否互质}

判断 list1 和 list2 的交集是否只有唯一的元素 1, 如果 是,说明 $\mathrm{M}$ 和 $\mathrm{N}$ 互质。获得集合的交集的常用方法一般有两 种,即循环遍历元素判断法和使用特定方法 retainAll(), 代码 如图 4 所示。

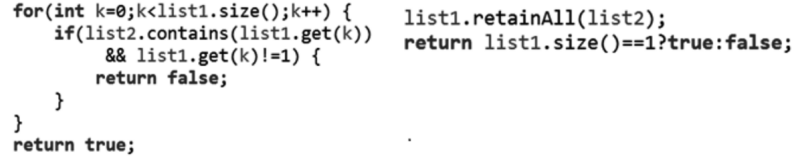

图 4 左侧是循环遍历判断法,右侧是使用 retainAll( )

\section{4 总结}

借助复杂的算法辅助编程去实现欧拉函数求解, 其代码 实现相对简单, 但实现代码可读性差, 对于算法的门槛要求较 高。通过上述步骤和方法实现欧拉函数求解, 其涉及到的算法 相对简单, 编程实现细节本身也不复杂, 代码的可读性更高, 主要涉及到 Java 课程中循环结构、集合等知识点, 非常适合 以实验或者实训的形式作为学生学习 Java 课程的一个环节。

\section{参考文献}

[1]传智播客高教产品研发部,Java 基础入门[M].北京:清华大学 出版社,2014.

\section{(上接第 128 页)}

学, 组织学生有计划有针对性地开展社会实践活动,开发并充 分利用其富有中国和地方历史文化特色的实践教学资源, 利 用寒暑假期间开展相关的社会实践活动，在实践中去服务于 人民, 奉献于社会 ${ }^{[3]}$ 。充分尊重培养学生在社会实践活动和教 学发展过程中的社会主体地位, 不断培养学生的综合理论知 识素质与自主创新能力, 从而有效地使《形势与政策》课程的 实践性教学内容能够内化于心, 外化于行。

\section{6 实行考核规范化和方法的多样化}

《形势与政策》课程的成绩可以采用学生的平时成绩与期 末考核成绩, 理论知识和实践学习成绩相结合的考核方法, 改 变一次期末考试定格的方式。平时成绩包括考勤、完成作业、 参与课堂活动等，实践活动的成绩也可以同时包括班级实践 活动和假期实践活动的综合成绩。这样的综合性考试考核的 形式和方法, 不仅灵活公平, 还充分锻炼了教师和学生的逻辑
思维能力和自主学习的能力。

\section{7 积极地建设优秀的教学资源共享网络平台}

高职院校应积极地建设《形势与政策》课程优质教学资源 共享的网络平台, 积极开展课堂网络化教学, 以校园教学网络 为主要教学依托, 设置网上教学的平台, 使其与网络课堂教学 相辅相成, 网络教学的平台可以为学生和教师提供《形势与政 策》课程优质教学的主要辅导材料, 也可以为授课的学生和教 师提供一个交流讨论互动沟通的空间和平台。

\section{参考文献}

[1]邢海晶. “形势与政策”课教学过程中的问题及对策研究 [J].科 教导刊,2017(4):88-89.

[2]葛彦东.高校形势与政策课教学过程中的结构性问题与其对 策 [J].大学生思想与教育实践问题研究,2010(12):79-82.

[3]丁玉涛.浅谈校园网的规划与设计 [J].黑龙江信息科技,2015 (35):201 . 